\section{Commercial One-row Bean Picker Harvests Vegetable Soybean}

\author{
Reuben B. Beverly ${ }^{1}$, \\ Allen W. Byous', and \\ Tommy Nakayama ${ }^{2}$
}

Additional index words. Glycine max mechanical harvest, small farm

Summary. Vegetable soybean (Glycine $\max$ L.) represents a potential highvalue specialty crop for small farmers in the southern Piedmont region of the United States; practical and affordable mechanical harvest technology will facilitate production. A trial planting of vegetable soybean was used to test the ability of a commercial one-row harvester used currently for snap bean and lima bean production systems to harvest soybean. The upright growth habit and excessive herbage of vegetable soybean necessitated harvest in two passes over the row, which produced in-pod yield of $7050 \mathrm{lb} /$ acre $\left(7900 \mathrm{~kg} \mathrm{ha} \mathrm{h}^{-1}\right)$. Adaptation of this technology has the potential to facilitate development of a vegetable soybean production industry.

$\mathrm{V}$ egetable soybean is popular in Japan, Korea, China, and Taiwan, where it is consumed either as a nutritious vegetable dish or as a snack(Laletal.,1991; Shanmugasundaram, 1991). In contrast to grain soybean, vegetable soybean is harvested before pods and seeds fully mature; they are generally larger, sweeter, and more tender than grain cultivars, although grain types also may be harvested immature and used as a vegetable. In Asia, seedbed preparation, sowing, and tillage are done by hand or with self-propelled planters or tillers. In addition, pods are usually harvested by hand-stripping them from plants,

Georgia Experiment Station, Griffin, GA 30223-1797. ${ }^{1}$ Dept. of Horticulture.

Dept. of Food Science and Technology. although mechanical harvesters also are used.

Grain soybean is a traditional crop in many regions of the United States, including the southern Piedmont. Vegetable legumes such as snap bean and lima bean also are grown for local markets or for shipping in this area (Beverly and Byous, 1992a, 1992b). Vegetable soybean production should be similar to and compatible with these other crops. The familiarity of local farmers with grain soybean production should facilitate and motivate adoption of vegetable soybean production, if a profitable market exists. The popularity of the crop among Asians and the presence of a significant Asian-American population in several U.S. metropolitan areas seem to provide that potential market. Local sales of fresh vegetable soybean is potentially lucrative, compared to imported frozen in-pod soybeans, which cost about $\$ 2.50 / \mathrm{lb}(\$ 5.50 / \mathrm{kg})$ at retail (M. Yamakami, personal communication).

Mechanical harvesting can facilitate vegetable soybean production. The cost and availability of hand-harvest labor constrains the production of many vegetable crops in this region, especially on small farms. A one-row harvester, designed originally for snap bean and adopted for lima bean harvest, was tested for application to vegetable soybean harvest.

We obtained seeds (cultivar unknown) from FWSS Soybeans, Ames, Iowa. The soybean planting followed a spring broccoli crop, and did not receive supplemental fertilizer above the residual of $400 \mathrm{lb} / \mathrm{acre}\left(448 \mathrm{~kg} \mathrm{ha}^{-1}\right)$ $13 \mathrm{~N} 5.7 \mathrm{P} 10.8 \mathrm{~K}$ applied the previous March. Broccoli residue was incorporated by rototilling prior to sowing soybean. Seeds were sown by hand on 16 June in three rows $60 \mathrm{ft}(18 \mathrm{~m})$ long. The final plant spacing of 5 inches $(13 \mathrm{~cm})$ in rows 32 inches $(80 \mathrm{~cm})$ apart produced a stand of 39,000 plants/acre $(97,000 / \mathrm{ha})$. The plots were sprinkler-irrigated to prevent prolonged drought stress. No pesticides were applied, and we did not observe any disease or insect damage. Weeds were controlled by rototilling and escaped weeds were hand-pulled prior to harvest. The only pest problem observed was minor browsing of upper leaves by deer just prior to harvest.

On 26 Aug., we harvested the plot using a commercial one-row bean 


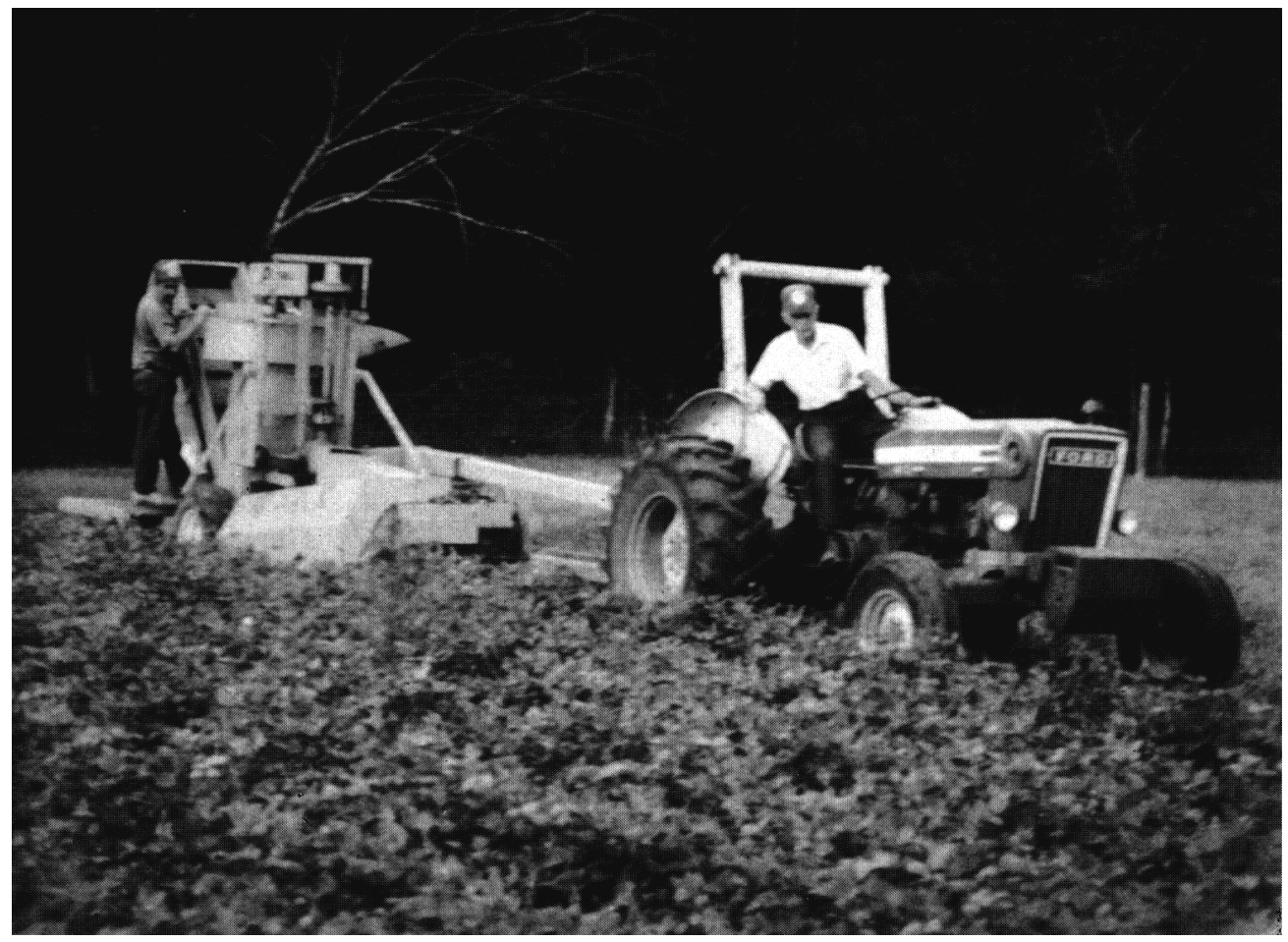

Fig. 1. The one-row bean harvester used in this study, shown here harvesting lima beans.

harvester (Pixall Corp., Clear Lake, Wis.) (Fig. 1). The harvester works by stripping leaves and pods from stems and branches by means of picker fingers on a rotating reel mounted at an incline parallel to the plant row. On the first row, the harvester clogged on the excessive herbage. The soybean, with lush growth 30 inches $(75 \mathrm{~cm})$ high, exceeded the height of the picking reel at the leading end. In addition, the thicker stems and denser foliage of soybean compared to other beans exceeded the capacity of the picker to strip leaves and pods from the stems. Stems and leaves wrapped around the picking reel and drive shaft at the leading end, causing the drive clutch to slip. When this occurred, stems had to be removed from the reel and drive shaft by hand. On the second row we tried running the picker at a higher tractor PTO speed (2000 rpm, rather than the usual $1500 \mathrm{rpm})$. This increased the loss of pods through the cleaning fan, but did not prevent clogging by stems and leaves. Finally, on the last row, we operated the harvester at its highest elevated (travel) position. By so doing, the harvester encountered the top 18 inches $(45 \mathrm{~cm})$ of plants, leaving the lower 12 inches (30 $\mathrm{cm}$ ) unharvested. By going over the row a second time with the harvester at normal picking height to recover this lower 12 inches, the plants were harvested satisfactorily, with no further problem arising due to excessive vegetative material.

Following harvest, the in-pod soybeans were graded to remove excess stems, leaves, and soil. More stems went through the picker and into harvested soybeans than we had observed with lima bean. This result made handcleaning after harvest more difficult than for other crops.

After cleaning, in-pod weight from the three-row plot was equivalent to $7050 \mathrm{lb} /$ acre $\left(7900 \mathrm{~kg} \mathrm{ha}{ }^{-1}\right)$. A sample was shelled using a mechanical lima bean sheller, and yielded a shellout of $32 \%$. These yield and shellout results are similar to favorable fresh-market lima bean yields of 225 to 250 bushels/acre. Seed size and shape are very similar to large Dixie Butterpea lima bean seeds [ 0.5 inch long, 0.3 inch wide, and 0.2 inch thick $(12 \times 8 \times 6$ $\mathrm{mm})]$, but the seed color is a much brighter green than Eastland or Thorogreen lima beans. Compared to lima bean as a boiled vegetable, soybean has a crunchier texture, less starchy or mealy flavor, and superior appearance. In addition, boiled and salted in-pod soybean (Japanese eda mame) was received favorably as a snack food.

Based on this preliminary trial, it appears that favorable yields and the feasibility of mechanical harvesting provide good potential for vegetable soybean production in the Piedmont region of the United States. These results are sufficient to justify additional research on production systems, handling, and marketing.

\section{Literature Cited}

Beverly, R.B. and A. W. Byous. 1992a. Ratoon cropping mechanically harvested lima bean is possible in the southern Piedmont. HortScience 27:269.

Beverly, R.B. and A.W. Byous. 1992b. Shelled lima bean as a value-added freshmarket specialty vegetable. Acta Hort. (In press.)

Lal, G., S.H. Lai, and S. Shanmugasundaram. 1991. Vegetable soybean cultivation. Asian Veg. Res. and Dev. Ctr. Publ. 91-357.

Shanmugasundaram, S. 1991. Vegetable soybean: Research needs for production and quality improvement. Workshop Proc. Kenting, Taiwan, 29 Apr.-2 May 1991. Asian Veg. Res. and Dev. Ctr. Publ. 91346. 